\section{Case Reports in Oncology}

\title{
Splenic Angiosarcoma: A Diagnostic Splenectomy Finding
}

\author{
Otavio Schmidt de Azevedo ${ }^{a}$ Bruna do Nascimento Santos ${ }^{b}$ \\ Nelson de Souza Liboni ${ }^{a}$ Juliano Fernandes da Costa ${ }^{a}$ \\ Olimpio Daniel de Campos ${ }^{\mathrm{a}}$ \\ ${ }^{a}$ Hospital Alemão Oswaldo Cruz, São Paulo, Brazil; ' Santa Casa de São Paulo Medical \\ School, São Paulo, Brazil
}

\section{Keywords}

Angiosarcoma $\cdot$ Soft-tissue sarcoma Splenic angiosarcoma $\cdot$ Angiosarcoma of the spleen

\begin{abstract}
Splenic tumors are not frequent. Blood vessel neoplasms are a rare category of tumors and have an extremely low incidence in the spleen. This case report aims to describe a 57-yearold woman in whom a routine imaging examination had shown splenic cysts. During her follow-up, the cysts became larger and increased in number. A diagnostic splenectomy was performed and its analysis showed a rare splenic angiosarcoma.

(C) 2016 The Author(s)

Published by S. Karger AG, Basel
\end{abstract}

\section{Introduction}

Angiosarcoma is a rare neoplasm and corresponds to less than $1 \%$ among soft-tissue sarcomas. The splenic involvement is a condition that was first described by Langhans [1] in 1879. Since then, about 150 cases have been reported in the literature [2]. These tumors are typically present in patients older than 40 years and have no gender predilection [3].

Some lesions are found incidentally on radiological examination; they are more commonly diagnosed due to acute abdominal symptoms secondary to rupture [4]. Anemia, thrombocytopenia, or other coagulopathies are possible complications [5]. 
Some data suppose a relation between previous or known malignancy and spleen tumor incidence. Isolated splenic metastases are rare; only 40 cases have been reported in the literature so far [6-8].

The prognosis is poor because this is an extremely aggressive tumor and $80 \%$ of the patients died by 6 months after diagnosis [3].

\section{Case Report}

A 57-year-old woman with an extensive medical history was diagnosed with angiosarcoma of the spleen. In 1991, she was diagnosed with breast ductal carcinoma (T2pN0p) and received a right quadrantectomy and radiotherapy (5,500 cGy total dose). In 2004, a partial thyroidectomy was carried out due to a papillary carcinoma. She was a carrier of polycystic kidney disease type 1, asthma, dyslipidemia and hiatal hernia.

In November 2012, she sought medical help for gastrointestinal discomfort that had become more intense a few months earlier. A high digestive endoscopy was performed showing short Barrett esophagus without dysplasia and hiatal hernia. She was treated with prokinetic and proton pump inhibitor drugs and dietary advice. In addition, abdominal ultrasound was performed showing splenic complex cysts; for better evaluation, magnetic resonance imaging (MRI) was requested.

Three months later, the MRI showed a single 2-cm cystic nodule, presenting a homogeneous content. An imaging monitoring was proposed for 6 months and gastric drugs were maintained for gastroesophageal reflux disease (GERD) control. On April 19, 2013, she went to the emergency service after 1 week of diffuse and nonstop abdominal pain, without peritonitis. A tomography scan showed splenic cysts that had increased in number and size. The CA 125 level was analyzed and presented a slight increase. The patient underwent a diagnostic laparoscopy splenectomy and the spleen was sent to pathological analysis.

The patient was discharged 2 days after surgery with no peri- or postoperative complications. The pathologic analysis described a spleen of $200 \mathrm{mg}$ weight, size $14 \times 10 \times 6 \mathrm{~cm}$, capsule smooth, gray, with interruption areas measuring $4 \mathrm{~cm}$ in length. The cut surface had a fine granular appearance of brownish color with wine-dotted areas. Microscopically, irregular nodular areas could be seen with areas of proliferation with elongated cells, arranged in bundles or around large vascular spaces with poorly defined cytoplasm and elongated nuclei and sometimes hyperstained. The mitotic index was low with large areas of bleeding. The diagnosis was vascular neoplasm found by immunohistochemical evaluation, which suggests angiosarcoma of the spleen.

Postoperative treatment was initiated 1 month after the procedure: 4 cycles divided into 12 infusions of paclitaxel chemotherapy and pazopanib were performed. A prior CT was performed showing no evidence of disease.

After 7 months of medical follow-up, the patient presented earlier gastrointestinal symptoms, and abdominal and thoracic imaging examinations showed no signs of disease. One year and 2 months after the surgery, in the following examination, the patient complained about neck pain and cervical imaging was performed. An MRI showed secondary bone lesion with contrast enhancement in the vertebral body of C7, with soft-tissue components projecting into the spinal canal (size $1.7 \times 1.5 \times 1.1 \mathrm{~cm}$ ). The diagnosis was metastatic angiosarcoma. Three months later, the $\mathrm{C} 7$ lesion was resected, replaced by a titanium implant followed by 10 radiotherapy sessions (total dose of 3,000 cGy). 
During 1 year and 1 month, the patient presented few symptoms, basically gastrointestinal symptoms due to GERD. However, although there was no evidence of local recurrence, the patient presented weight loss, immunodeficiency signs and hypoalbuminemia, suggesting a consumptive syndrome. The consumptive syndrome further evolved followed by impairment of the immunologic system. The patient was diagnosed with bronchopneumonia and developed sepsis. She died in February 2016, more than 3 years after the diagnosis.

\section{Discussion}

Angiosarcoma of the spleen is a very rare malignancy and this term is used to report a primary tumor of the spleen. However, angiosarcoma can also rarely be a metastatic tumor to the spleen. Angiosarcomas correspond to less than $1 \%$ of soft-tissue sarcomas, and a smallest fraction occurs in the spleen [9].

Nontraumatic splenic lesions are mostly incidental findings. The splenic cysts are usually detected on radiologic examination and surgery due to other reasons, or autopsy, but some larger cysts may present with abdominal pain and gastrointestinal symptoms [10]. Our patient presented a prior radiologic diagnosis of a single 2-cm cystic nodule and gastrointestinal discomfort, but these symptoms were assigned to GERD.

Angiosarcoma presents with no gender predilection and is most common in individuals older than 40 years [3]. Anemia, thrombocytopenia, other coagulopathies and acute abdominal pain secondary to rupture are the most common clinical conditions in symptomatic patients $[4,5]$. The epidemiology fits in our patient, except for the coagulopathies. Her abdominal pain was assigned to an acute expansion, probable bleeding or internal splenic lesion rupture.

This type of sarcoma is aggressive and the 6-month survival is about 20\%. Approximately $70 \%$ of cases have liver metastases [3]. Other sites of metastases are bone, bone marrow and the lymphatic system [11]. Our patient remained with no signs of disease for 1 year and survived for 3 years and 9 months, which is more than expected. The site of her metastases corresponds to what had been found in the literature.

Some case reports indicate an association with previous chemotherapy for lymphoma, radiation therapy for breast cancer and thorotrast exposure, and malignancy of the spleen [3]. Two autopsy series conducted by Rane et al. [12] and Schon et al. [13] showed that the incidence of splenic neoplasms was $1.45 \%$ and that metastases to the spleen occurred in $3 \%$ of the cases, respectively $[14,15]$. Lung cancer, melanoma and breast cancer are the most primary tumor sites in spleen metastases [15].

Although our patient underwent a prior radiotherapy treatment for breast cancer, the site of radiation was contralateral to the spleen. In addition, radiation-induced sarcoma is usually found in children due to growth tissue. On the other hand, the prior breast cancer could be the responsible for splenic metastases, supporting Schon et al.'s findings.

The definitive diagnosis could be made by pathological analysis of diagnostic splenectomy or by biopsy. Recent studies have reported success rates of splenic biopsy ranging from 63 to 89\%, with complication rates ranging from 1.5 to $13 \%$ [16-20]. A common complication is bleeding and the range is from 0 to $2 \%$ and it is most frequent in vascular lesions. Therefore, diagnostic splenectomy is a frequent choice in such cases.

Adjuvant chemotherapy is a controversial treatment option because there is no evidence to suggest a clinical benefit from this choice [21]. Neuhauser et al. [22] reported a study of 28 patients who were treated with splenectomy, and a small part of them received 
adjuvant chemotherapy. One patient survived with the disease for 8 years and another was disease free for 10 years. Except for these 2 cases, the median survival rate was 5 months for the remaining 26 patients [23].

Paclitaxel use had already been reported as an adjuvant and neoadjuvant therapy by Vakkalanka and Milhem [24], suggesting that the unresectable tumor became resectable, thus improving survival with postoperative therapy. Our patient remained disease free for 1 year and 2 months after paclitaxel adjuvant chemotherapy.

Thus, this case corroborates many aspects found in the literature, although other aspects challenge the known numbers and statistics data. This means that etiology, survival and treatment of splenic angiosarcoma remain unclear and there is not yet a consensus.

\section{Statement of Ethics}

Consent for publication was obtained from the patient's family. All data exposing patient identification have been omitted.

\section{Disclosure Statement}

The authors have no conflicts of interest to disclose.

\section{References}

1 Langhans T: Pulsating cavernous neoplasm of the spleen with metastatic nodules to the liver. Virchows Arch 1879;75:273-291.

2 Muzi MG, Rulli F, Federico F: Angiosarcoma of the spleen mimicking rupture: case report and literature review. Acta Biomed Ateneo Parmense 2000;71:135-140.

-3 Abbott RM, Levy AD, Aguilera NS, et al: From the archives of the AFIP: primary vascular neoplasms of the spleen: radiologic-pathologic correlation. Radiographics 2004;24:1137-1163

4 Kawamoto S, Fishman EK: MDCT evaluation of the spleen; in Fishman EK, Jeffrey RB Jr (eds): Multidetector CT: Principles, Techniques, Clinical Applications. Philadelphia, Lippincott Williams and Williams, 2004, pp 255-269.

5 Ahmed S, Horton KM, Fishman EK: Splenic incidentalomas. Radiol Clin North Am 2011;49:323-347.

-6 Lam KY, Tang V: Metastatic tumors to the spleen: a 25-year clinicopathologic study. Arch Pathol Lab Med 2000;124:526-530.

7 Klein B, Stein M, Kuten A, et al: Splenomegaly and solitary spleen metastasis in solid tumors. Cancer 1987;60:100-102.

-8 Schmidt BJ, Smith SL: Isolated splenic metastasis from primary lung adenocarcinoma. South Med J 2004;97:298-300.

9 Venegas LF, Pohlmann PR, Balbinot AL, Schuck E, de Oliveira CTM, Frank KJ, Dillemburg CF, da Costa MSB, Rivero LFR, Pütten ACK: Angiossarcoma primário de baço: relato de caso e revisão da literatura. Rev Bras Cancerolog 1998;44:12-14.

10 Rabushka LS, Kawashima A, Fishman EK: Imaging of the spleen: CT with supplemental MR examination. Radiographics 1994;14:307-332.

11 Freeman JL, Jafri SZ, Roberts JL, et al: CT of congenital and acquired abnormalities of the spleen. Radiographics 1993;13:597-610.

12 Rane SR, Bagwan IN, Pingle P, et al: Splenic tumors - autopsy study of ten years. Indian J Pathol Microbiol 2005;48:186-189.

13 Schon CA, Georg C, Ramaswamy A, et al: Splenic metastases in a large unselected autopsy series. Pathol Res Pract 2006;202:351-356.

14 Hansen MB, Moller AC: Splenic cysts. Surg Laparosc Endosc Percutan Tech 2004;14:316-322.

15 Urrutia M, Mergo PJ, Ros LH, et al: Cystic masses of the spleen: radiologic-pathologic correlation. Radiographics 1996;16:107-129. 
-16 Keogan MT, Freed KS, Paulson EK, et al: Imaging-guided percutaneous biopsy of focal splenic lesions: update on safety and effectiveness. AJR Am J Roentgenol 1999;172:933-937.

-17 Caraway NP, Fanning CV: Use of fine-needle aspiration biopsy in the evaluation of splenic lesions in a cancer center. Diagn Cytopathol 1997;16:312-316.

-18 Venkataramu NK, Gupta S, Sood BP, et al: Ultrasound guided fine needle aspiration biopsy of splenic lesions. Br J Radiol 1999;72:953-956.

19 Metser U, Miller E, Kessler A, et al: Solid splenic masses: evaluation with ${ }^{18} \mathrm{~F}-\mathrm{FDG}$ PET/CT. J Nucl Med 2005;46:52-59.

20 Metser U, Even-Sapir E: The role of ${ }^{18}$ F-FDG PET/CT in the evaluation of solid splenic masses. Semin Ultrasound CT MR 2006;27:420-425.

21 Shukla M, Basu S, Shukla VK, Kumar M: Fever, anemia, and splenomegaly: a rare presentation of splenic angiosarcoma. Indian J Med Paediatr Oncol 2011;32:230-232.

22 Neuhauser TS, Derringer GA, Thompson LDR, et al: Splenic angiosarcoma: a clinicopathologic and immunophenotypic study of 28 cases. Mod Pathol 2000;13:978-987.

23 Targarona EM, Espert JJ, Balague C, Piulachs J, Artigas V, Trias M: Splenomegaly should not be considered a contraindication for laparoscopic splenectomy. Ann Surg 1998;228:35-39.

24 Vakkalanka B, Milhem M: Paclitaxel as neoadjuvant therapy for high grade angiosarcoma of the spleen: a brief report and literature review. Clin Med Insights Oncol 2010;4:107-110. 